\title{
A trip to Mount Trus MADI - THE NEPENTHES WONDERLAND
}

Alviana Damit • Forest Research Centre • Sabah Forestry Department • P. O. Box 1407 • 90715 Sandakan Sabah•Malaysia・Alviana.Damit@sabah.gov.my

Keywords: Nepenthes, Mount Trus Madi, Sabah, Borneo.

As a carnivorous plant enthusiast, have you ever wondered what it is like to be in a deep tropical jungle with plenty of wild pitcher plants dangling and scrambling around? Well then, prepare to stretch your imagination and let me share with you my journey to Mount Trus Madi. A place I call a Nepenthes wonderland.

Located in Sabah and standing at $2642 \mathrm{~m}$ above sea level, Mount Trus Madi is the second highest mountain in Malaysia. My four-day trip in May 2013 was part of a botanical and ecological exploration in the Trusmadi Forest Reserve, in which this mountain is located. We started hiking early in the morning from the Kaingaran Trail starting point at $1631 \mathrm{~m}$ a.s.l. The distance to the summit from this point is about $4.9 \mathrm{~km}$. At the moment, this trail is closed to public due to upgrading of some tourism facilities.

After less than an hour of hiking, we found our first pitcher plant beside the boardwalk. It was a dainty little Nepenthes tentaculata (Fig. 1) creeping on the mossy forest floor. The plant can be easily identified by its signature tentacle-like hairs on its lid and diamond-shaped mouth. This species is so abundantly seen throughout the entire trail that you could hardly avoid from stepping on them unintentionally. They were either climbing on the treelets or creeping on the mossy ground. The pitcher sizes we saw ranged from as small as $1 \mathrm{~cm}$ to $13 \mathrm{~cm}$ in length. Their colors appeared in various hues, including yellow, green, red to dark purple.

A clump of Nepenthes stenophylla (Fig. 2) was found growing terrestrially at $1700 \mathrm{~m}$ a.s.1. It only had two pitchers with the biggest one measuring about $20 \mathrm{~cm}$ in length. The cylindrical pitchers with beautiful dark purple streaks have a round lid and rounded boss at the base of the lid, which are the distinctive features of this species. That is the only clump I found along the summit trail. Over

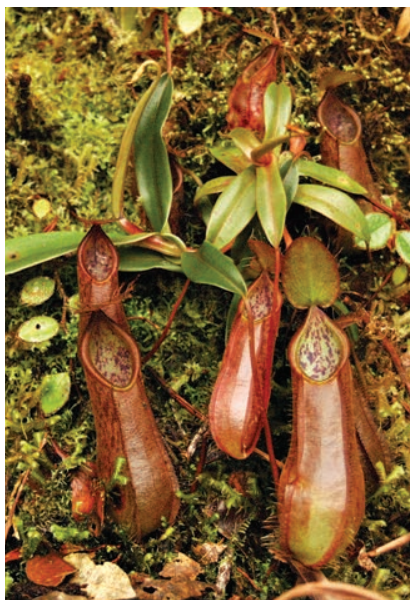

Figure 1: Nepenthes tentaculata.

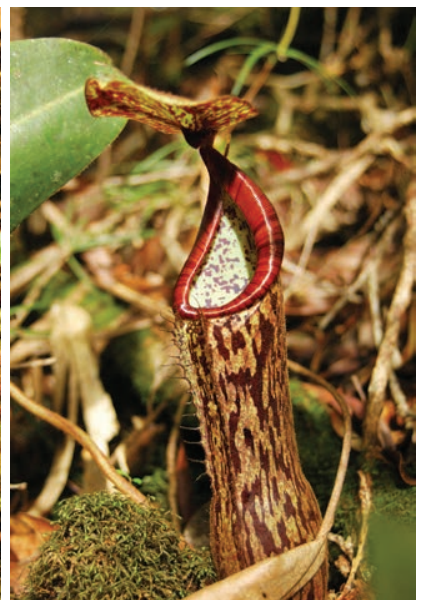

Figure 2: Nepenthes stenophylla.

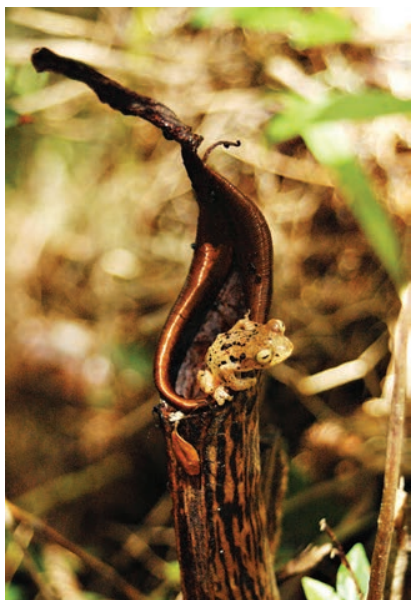

Figure 3: A small montane bush frog perched on the rim of Nepenthes fusca. 


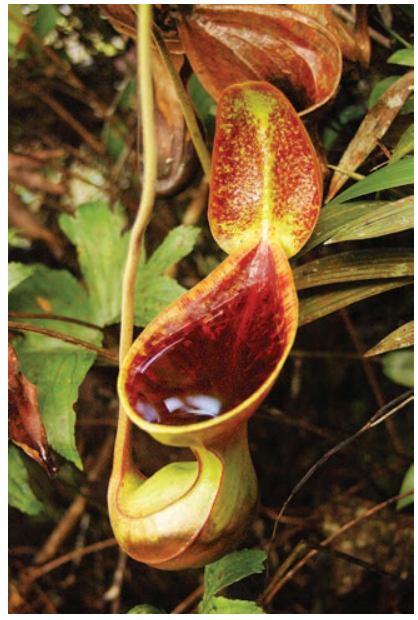

Figure 4: Nepenthes lowii.

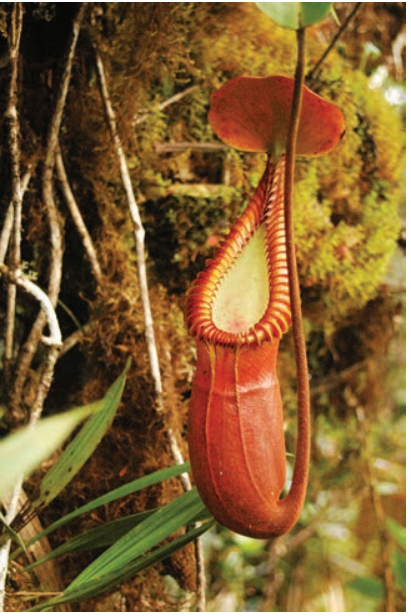

Figure 5: Nepenthes macrophylla.

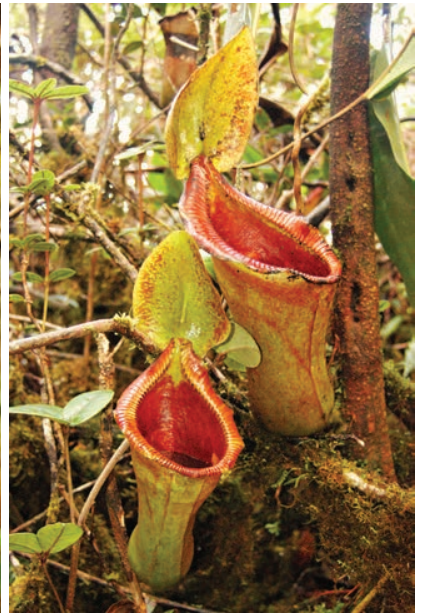

Figure 6: Nepenthes $\times$ trusmadiensis, a natural hybrid between $N$. lowii \& N. macrophylla.

the next few days, I found another $N$. stenophylla on a ridge top at the same approximate elevation on a different area of the reserve.

Instead of focusing on the trail path I was on, my eyes were all over the forest ground and the tree tops looking for Nepenthes. The stunted trees and the damp ground in this tropical montane forest were literally enveloped with thick layers of mosses. The air was comfortably chilly at about $20^{\circ} \mathrm{C}$ and was occasionally misty. Combined with complete silence and low lighting, I found myself in a mystical and beautiful surrounding.

At the 1962 m elevation ridge top, the area is more exposed and sunny. All of us were captivated by a striking red flower blossom of Rhododendron fallacinum, a Sabah endemic plant. On this ridge top, I also found a Nepenthes fusca shrub. There were only two pitchers and they were almost dried out, measuring about $15 \mathrm{~cm}$ long. We cut the plant tip with one pitcher attached for our specimen collection. It is part of my routine to inspect the content of the pitcher before emptying it out. All of a sudden, I let out a loud shriek when I found myself just centimeters away from a tiny frog inside the pitcher! Throwing away the pitcher startlingly was part of the reflex and my tripmate nearly fell off the ridge. After we had a good laugh at it, I asked him to place the frog on the N. fusca peristome so we could shoot a great picture (Fig. 3). This photogenic frog could likely be Philautus aurantium, a small montane bush frog endemic to Borneo.

Hiking up to the higher elevation, the temperature was getting cooler and the vegetation is gradually changing to shorter and stunted plants, called mountain scrub. The gnarled and twisted trees along the ridge top trail seem like an exquisite bonsai garden. The entire air was a complete white thick fog and it shortened our vision. I felt like walking above the cloud in a mysterious garden.

Here, I discovered several big astonishing bunches of Nepenthes lowii hanging down from the stunted trees! They have the most distinguished pitchers due to their peculiar shape (Fig. 4). The sturdy narrow-waist pitchers are up to $25 \mathrm{~cm}$ long, mostly green on the outside and deep red inside. It was such a joyful find that my weariness after 7 hours of trekking had disappeared. I then truly understood how Nepenthes got its name; from the drug-of-forgetfulness called 'nepenthe' by the world renowned botanist, Carl Linnaeus in 1897. 


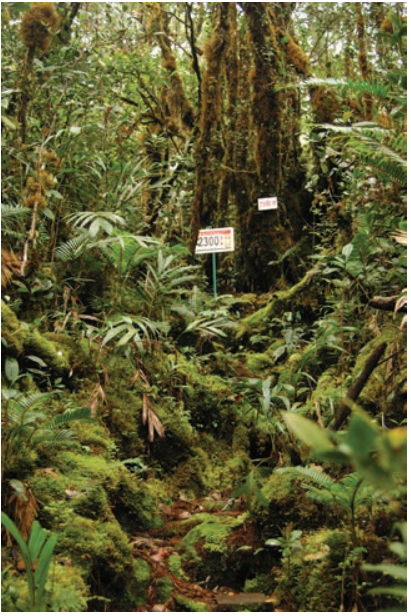

Figure 7: The trail in the mossy forest.

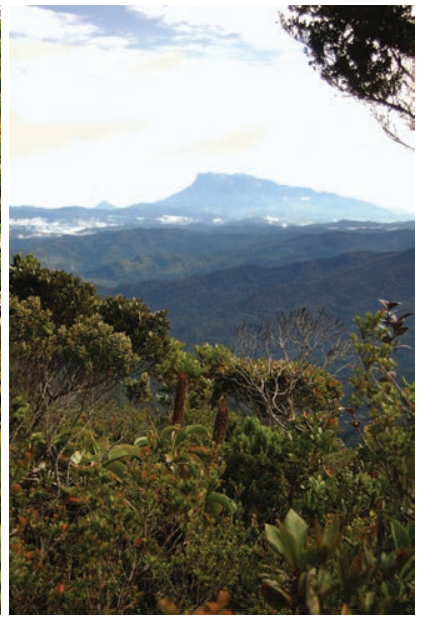

Figure 8: Mount Kinabalu seen at the north horizon from the ridge top summit trail.

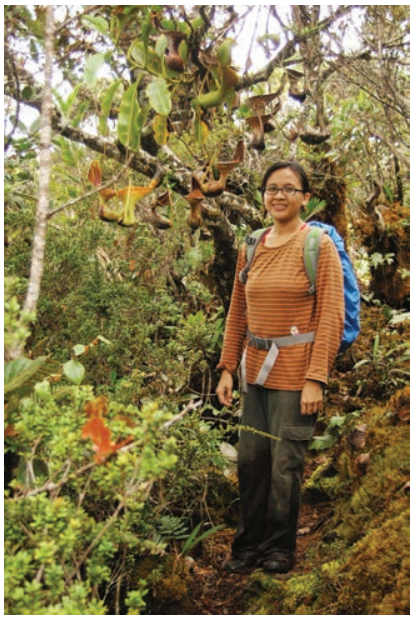

Figure 9: Author with a bunch of $N$. lowii hanging above.

We dawdled through the beautiful natural surroundings. Our laggard group arrived at the Gibon cabin at 4:30 pm. We spent a cold and damp rainy night, with a temperature of about $14^{\circ} \mathrm{C}$ and $99 \%$ humidity in the cabin, which could fit 18 people. We planned to wake up as early as 4 am to catch the sunrise at the summit. Unfortunately, when we awoke, it was still drizzling. We then began another $1.5 \mathrm{~km}$ journey to the peak at about $6 \mathrm{am}$.

While I thought I had seen the forest as beautiful as it could be the day before, the trail to the summit was even more spectacular. Within just $10 \mathrm{~m}$ of the cabin, I saw some amazing epiphytes of Nepenthes macrophylla and a natural hybrid Nepenthes $\times$ trusmadiensis (N. lowii $\times$ N. macrophylla). Both species are endemic and exclusively found only on this mountain.

The broadly cylindrical pitchers of $N$. macrophylla are up to $35 \mathrm{~cm}$ long and have an impressive peristome with a series of vertical flanges (Fig. 5). The colors range from bright red to orange. Together with $N$. lowii, these fine Borneo pitcher plants occur in the deep mossy forest and the bonsai garden. Their countless amazing pitchers were dangling all over the area like Christmas ornaments. The scene was truly an enchanting Nepenthes garden!

Unlike its abundant parents, the $N . \times$ trusmadiensis was not that easy to spot. We only managed to find two along the way, about 800 meters apart. One of which was a ground scrambler (Fig. 6) that produced a large pitcher of about $40 \mathrm{~cm}$ long, from base to reflexed scoop lid.

The trail was quite challenging (Fig. 7). Some knee-shaking steep parts required us to climb up with a rope, occasionally pulling and stepping on exposed tree roots. The path was also boggy and the clumsy members of our team often tripped when accidentally stepping on slippery rocks or roots. In spite of this, we were lucky to have a clear bright sky that enabled us to view the breathtaking panoramic scenery from the ridge top. The famous majestic Mount Kinabalu could be seen standing on the northern horizon, about $50 \mathrm{~km}$ away from where we stood (Fig. 8). We finally reached the summit of Mount Trus Madi at $10 \mathrm{am}$.

Trekking down to the cabin was faster, which took us only about 2 hours. After we had lunch and packed our belongings, we quickly went down and raced against time to reach the starting point before it got dark at $6 \mathrm{pm}$. 
As we headed home a few days later, I looked back at the mountain and smiled gratefully, enriched with my wonderful experience. The Mount Trus Madi trip is one of the most memorable adventures I have ever had and I will always remember it as a Nepenthes wonderland.
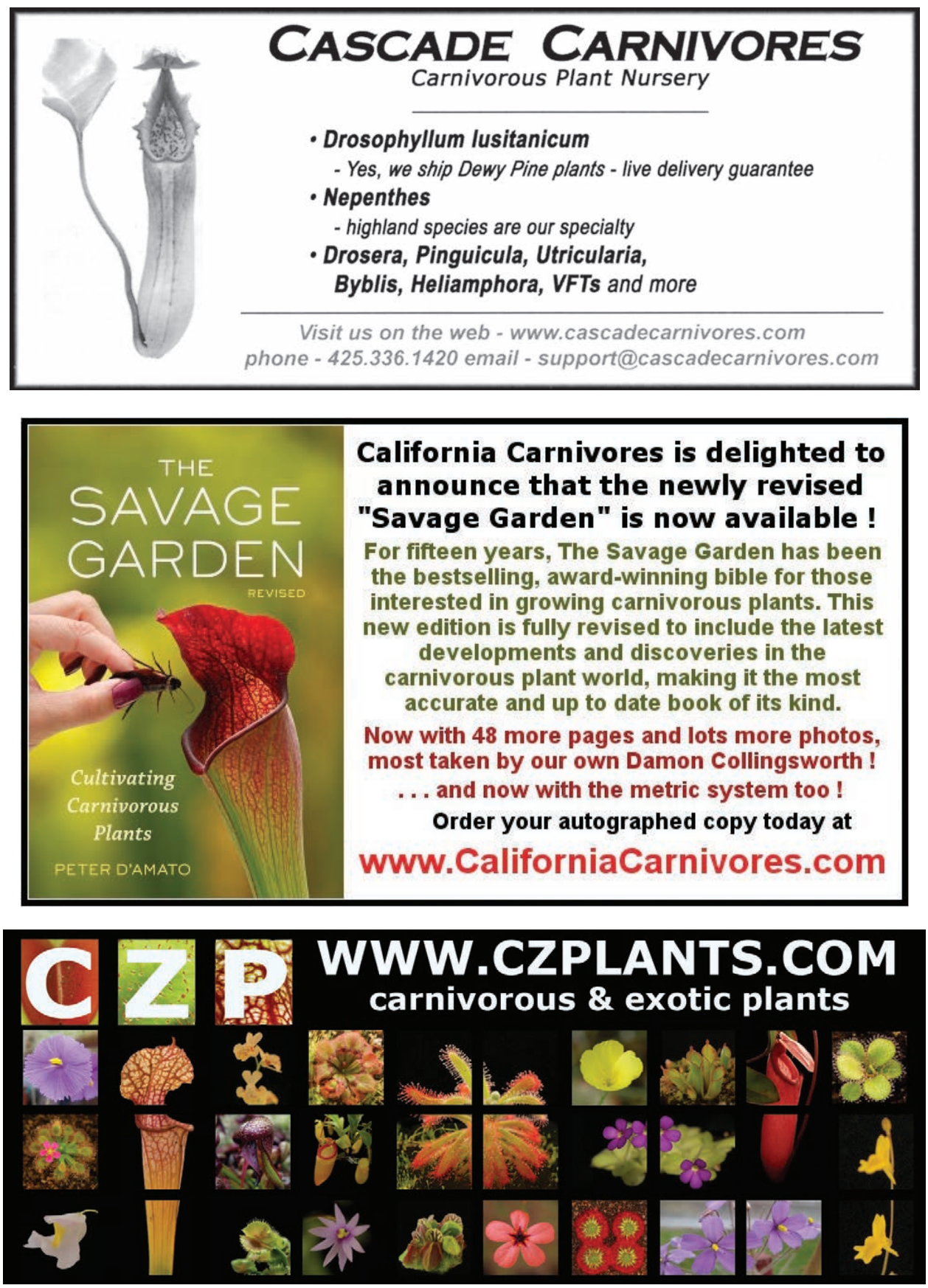